\title{
S5ynthesis
}

International Scientific Conference of IT and Business-Related Research

\section{GRAFIČKA ORGANIZACIJA I IZVRSNOST}

\section{GRAPHIC ORGANIZATION AND EXCELLENCE}

\author{
Srđan Stanojković \\ Univerzitet Singidunum, Danijelova 32, Beograd
}

\begin{abstract}
Apstrakt:
Ovaj rad sadrži istraživanje koje govori o sposobnosti grafičke industrije Srbije da posluje u skladu sa načelima poslovne izvrsnosti. U radu se ispituju različite metode i njihova struktura: kriterijumi MH modela izvrsnosti, forme PROPR matrice, statistička metoda kontrolne karte, itd. Interviju je vođen sa vodećim grafičkim organizacijama na ovim prostorima koje izrađuju široki spektar grafičkih proizvoda. Prikazani su rezultati analiza navedenih metoda, zaključci i moguća rešenja. Preporučena je paradigma modela poslovne izvrsnosti specifična za grafičku industriju sa nezaključanim kriterijumima i otvorena za nadolazeće promene i zahteve okruženja.
\end{abstract}

\section{Ključne reči:}

grafička organizacija, statistička metoda, poslovni jaz, poslovna izvrsnost.

\section{UVOD}

Koncept izvrsnosti se bazira na izvanrednoj praksi i globalnog je karaktera.

Ciljevi poslovne izvrsnosti sadrže:

- visok nivo performansi poslovanja u poređenju sa domaćom i inostranom konkurencijom;

- iskazivanje dugoročnih trendova poboljšanja u svim aspektima procesa poslovanja;

- postojanje i primenu metoda i aktivnosti TQM u celokupnoj organizaciji.

Globalna tržišna privreda ne prepoznaje primitivne organizacije i organizacije sa tradicionalnim menadžment stilom koje su uglavnom zastupljene u našoj i privredi zemalja u tranziciji (time i u grafičkoj industriji Srbije). Prisustvo na globalnom tržištu zahteva od organizacija da naprave radikalan strateški zaokret, od problemski orijentisanog sistema ka inovativnom menadzment stilu (Heleta, 2010).

\section{NIVO POSLOVNOG ORGANIZOVANJA}

\section{Tradicionalni oblik poslovanja}

Primitivna organizacija. Najniži nivo primitivne organizacije jeste improvizacija (rad bez pravila). Kod ovakve organizacije, kvalitet je suvišan u bilo kom obliku. Vezuje se za protekcionističku i monopolističku privredu, špekulativnog karaktera. Odlikuje je progresivno generisanje problema i manjkavost proizvoda, što organizaciju vodi u propast i stanje haosa.

\begin{abstract}
:
This paper presents research that examines the capabilities of the graphic industry in Serbia to operate in accordance with the principles of business excellence. The paper analyses various methods and their structure: criteria of MH models of excellence, PROPR matrix forms, statistical methods of control charts etc. An interview was conducted with the leading graphic organizations in the region that produce a wide range of graphic products. The results of the given methods are presented along with the conclusions and possible solutions. A paradigm of business excellence model has been recommended, which is typical for the graphic industry with unlocked criteria, and open for the upcoming changes and demands of the market.
\end{abstract}

\section{Key words:}

graphic organization, statistical methods, business gap, business excellence.

Organizacija tradicionalnog stila menadžmenta. Zastupljenost tradicionalnog stila menadžmenta vodi statičnosti, čija je posledica propadanje organizacije, jer sve se menja oko organizacije. Tradicionalni menadžment usmeren je ka rešavanju tekućih problema, kratročnim ciljevima i improvizaciji. Organizacije sa tradicionalnim menadžmentom ne prihvataju poboljšanja, proboje ili inovacije. Primena spoljnih mentalnih modela im je strana. Deklarativno prihvatanje standarda i njihovo sprovođenje kod organizacija problemskog menadžmenta ne dovodi do rezultata. Organizacija ne primećuje eksterne promene, ne beleži rast i ne poseduje ekonomsku konkurentnost. Najveći domet ovako uređenih organizacija je u domenu monopolskih povoljnosti, gde dolazi do zadovoljavanja trenutnih planskih potreba kupca, ne obazirući se na kvalitet i inovativnost proizvoda.

Ovakve organizacije se ne obaziru na ekonomičnost poslovanja, korišćenje resursa (obnovljivi/neobnovljivi), ili obaveze prema društvu (Heleta, 2008).

Inovativni menadžment stil je orijentisan na dugoročne preventivne mere, uz istovremeno upravljanje aktuelnim promenama, stalnim poboljšanjima i inovacijama. Uz stalna poboljašanja rezultati ovakvog poslovanja su održivi rast i permanentno približavanje ciljevima poslovne izvrsnosti. Promena u pristupu kvalitetu nastaje promenom samog koncepta obezbeđenja kvaliteta. Novi pristup koji obezbeđuje kvalitet jeste prevencija otkaza (proaktivnim prilazom) za razliku od skorašnjeg "kontrolisanja kvaliteta" (Heleta, 2010).

Menadžment sistem (MS) predstavlja skup međusobno povezanih elemenata za uspostavljanje politike i ciljeva organizaci- 
je, kao i odabir načina za njihovo ostvarenje. Svaka organizacija ima menadžment sistem koji može primenjivati različite MS kao što su: menadžment sistem kvaliteta, menadžment sistem životne sredine, itd.

Metod sadržan u aktivnostima QMS jeste: planiraj-komanduj ili realizuj-kontroliši (Heleta, 2010).

Totalni kvalitet menadžmenta (TQM). Evolucija kvaliteta od menadžmenta kvaliteta ka kvalitetu mendžmenta dovodi do najvišeg nivoa novog koncepta kvaliteta (Total Quality Management) i predstavlja odgovor na ubrzane promene u okruženju čiji su generatori “zainteresovane strane”. On je istovremeno, vrhunski nivo koncepta unapređenja kvaliteta i vrhunski nivo koncepta menadžmenta. TQM svojim konceptom ostvaruje sinergiju kvaliteta horizontalnih i vertikalnih procesa, procese kontinualnih poboljšanja i inovacija, i procese podrške. Za TQM ne postoji međunarodni standard. U njegovoj impementaciji učestvuju svi zaposleni, a on se u praksi realizuje preko modela izvrsnosti.

Metod koji primenjuje TQM je: planiraj-komanduj ili realizuj-kontroliši-poboljšaj (Heleta, 2010).

Poslovna izvrsnost (Business Excellence) se definiše kao visok nivo zrelosti organizacije u odnosu na upravljanje i postizanje poslovnih rezultata. Model izvrsnosti nije standard, već kreativni okvir zasnovan na kriterijumima koji služe za definisanje mesta i nivoa poslovnosti organizacije. Njegova osnovna metoda jeste benchmarking - upoređivanje sa drugima i učenje na njihovim iskustvima. Struktura modela izvrsnosti smeštena je unutar strukture TQM-a, dok kriterijumi modela izvrsnosti predstavljaju njegovu operacionalizaciju. Kriterijumi su kao i modeli izvrsnosti uslovljeni društvenim osobenostima određene zemlje.

Prelazak organizacije tradicionalnog oblika poslovanja u inovativni menadžment stil poslovanja, uslovljen je sposobnošću organizacije da prepoznaje promene, razume neophodnost rasta i održivog razvoja organizacije. Primenom kontinualnih poboljšanja i inovacija, organizacija doseže nivo kada su promene (interne/eksterne), rast i razvoj komplementarni faktori koji za cilj imaju izvrsnost interne organizacije i njenih rezultata. $\mathrm{Na}$ taj način se organizacija preobražava od organizacije "menadžmenta haosa" u organizaciju koja posluje "po modelu poslovne izvrsnosti” (Heleta, 2010).

Na putu ka izvrsnosti organizacija nailazi na više prepreka koje mora prevazići i to:

- poslovno-tehnološki jaz;

- organizacioni jaz;

- kulturološki jaz;

- jaz između krajnjih tačaka, raznolikosti i društvene odgovornosti (Heleta, 2010).

\section{ISTRAŽIVANJE}

Sprovedeno je istraživanje sa ciljem da se odgovori na hipotezu: da li je moguća primena modela poslovne izvrsnosti na grafičku organizaciju Srbije?

Osnovni pristup ovog istraživanja sproveden je kroz teoriju odlučivanja i primenu različitih metoda. Korišćen je princip kvalitativnog istraživanja u razumevanju pojave i izgradnji teorije, upotrebom metode malog uzorka i benčmarking metoda u analizi elemenata. Glavni izvor informacija bio je direktni kontakt, intervju (podaci iz izveštaja) dobijeni od grafičkih organizacija Srbije. Istraživanje se sastoji iz tri ključne celine. U prvoj celini urađeno je uzorkovanje delimično na osnovu metode logike PROPR matrice i uz primenu kriterijuma $\mathrm{MH}$ modela poslovne izvrsnosti (tabela 1). U drugoj celini na dobijene po- datke uzorkovanja primenjena je statistička metoda kontrolne karte (tabela 2). U trećoj celini na dobijene rezultate statističke metode kontrolne karte, primenjena je suština teorije odlučivanja i analiza postojanja poslovnog, tehnološkog, organizacionog, kulturološkog i jaza raznolikosti u grafičkoj industriji Srbije. Na kraju istraživanja predstavljena je i paradigma modela poslovne izvrsnosti specifična za primenu u grafičkoj industriji Srbije (tabela 3).

\section{STATISTIČKA METODA: KONTROLNE KARTE}

Kontrolna karta predstavlja efikasan alat za uspostavljanje, regulisanje i upravljanje procesom, čiji se produkt (kvalitet proizvoda/procesa) koristi u proizvodnim i uslužnim organizacijama na svim nivoima poslovanja.

Ključna primena je u svim fazama nekog procesa kao:

- ulazna, procesna, izlazna kontrola i kontrola proizvoda u kasnijoj eksploataciji,

- primena u serijskoj i masovnoj proizvodnji (osim ručne pojedinačne izrade proizvoda).

Koriste se i za upravljanje kvalitetom procesa rada i poslovanja, za faznu kontrolu kvaliteta proizvoda, usavršavanje i poboljšanje tehnološkog procesa rada sa stanovišta kvaliteta ili za analizu sistema grešaka iz tehnološkog procesa.

\section{KARAKTERISTIKE KVALITETA I STATISTIČKE MERE}

Katakteristike kvaliteta (proizvoda, usluga ili procesa) mogu biti: numeričke ili atributivne.

Numeričke karakteristike proizvoda nazivaju se varijablama i javljaju se kao: dimenzije proizvoda, gustina pare u atmosferi ili visina zaposlenih, a mere se odgovarajućom opremom. Statističke mere numeričkih karakteristika kvaliteta kojima se izražavaju kontrolne karte su:

- aritmetička sredina (x);

- raspon uzoraka $(\mathrm{R})$;

- standardna devijacija $(\sigma)$;

- izmerena vrednost karakteristike kvaliteta (x).

Atributivne karakteristike proizvoda se definišu opisno, konstatuju se i zbrajaju: broj reklamacija ili određivanje kvaliteta uzorka (dobro - loše).

Statističke mere atributivnih karakteristika kvaliteta kojima se izražavaju kontrolne karte su:

- broj neusaglašenih primeraka u uzorku (m);

- procenat neusaglašenih primeraka u uzorku ( $\mathrm{p}=100 \mathrm{~m} / \mathrm{n})$;

- broj neusaglašenosti u uzorku (c);

- broj neusaglašenosti po jednom primerku u uzorku $(\mathrm{u}=\mathrm{c} / \mathrm{n})$.

$\mathrm{Na}$ kontrolnoj karti razlikuju se tri osnovne linije (Kostić, 2004):

- Centralna linija, CL (predtsavlja srednju nominalnu vrednost, X0);

- Linija gornje kontrolne granice, GKG;

- Linija donje kontrolne granice, DKG.

Kontrolna karta može posedovati još dve pomoćne linije ispod i iznad gornje i donje kontrolne granice. One definišu donju i gornju upozoravajuću granicu (DUG i GUG) i predstavljaju vrednosti koje signaliziraju da proces ima tendenciju nestabilnosti, odnosno da je potrebno povećanom pažnjom pratiti rezultate narednih merenja (Kostić, 2004).

Opšti postupak izrade kontrolnih karata:

- Odabir karakteristika kvaliteta objekta, (jedne ili više); 
- Način biranja, veličine uzorka i vremena uzimanja;

- Izbor statističkih mera koje će se primeniti u izradi ka$\operatorname{rata}(\mathrm{x}, \mathrm{R}, \sigma, \mathrm{p}, \mathrm{m}, \mathrm{c}, \mathrm{u})$;

- Izdrada kontrolne lista kontrolnih karata;

- Izrada kontrolnih karta (Kostić, 2004).

Praktično to izgleda tako što se najpre se formira plan kontrolisanja procesa koji sadrži vreme i lokaciju uzimanja uzoraka. Zatim sledi merenje (ocena) vrednosti izabranih karakteristika kvaliteta i njihovo obračunavanje predviđenom procedurom i formulama. Dobijeni rezultati se unose u kontrolnu kartu čime ona postaje pregledna slika kvaliteta u vremenskom odvijanju procesa i izrađuje se kontrolna karta. Ukoliko su izračunate vrednosti, unutar kontrolnih granica (linija), smatra se da je proces stabilan (tj. da je pod statističkom kontrolom). U suprotnom proces je nestabilan i van statističke kontrole.

\section{VRSTE KONTROLNIH KARATA I NJIHOVA NAMENA}

U odnosu na oblike karakteristika kvaliteta (proizvoda, usluga ili procesa) kontrolne karte mogu biti:

Kontrolne karte za numeričke karakteristike kvaliteta - Ove kontrolne karte su namenjene obeležjima (proizvoda, usluga ili procesa) koja se mogu meriti adekvatnom mernom opremom. Koriste se u paru (x:R) ili (x: $\sigma)$, gde su aritmetička sredina (x), raspon uzoraka $(\mathrm{R})$ i standardna devijacija $(\sigma)$.

Parovi kontrolnih karata za numeričke karakteristike kvaliteta obuhvataju:

- $\mathrm{x}: \mathrm{R}$ par kontrolnih karata koji se primenjuje na manjim uzorcima, $\mathrm{n} \leq 10$ (primenjen u ovom radu);

- $\mathrm{x}: \sigma$ par kontrolnih karata koji se primenjuje na većim uzorcima, $\mathrm{n}>10$;

- $\mathrm{x}$ :R par kontrolnih karata koji se primenjuje za individualno praćenje kvaliteta (Kostić, 2004).

Kontrolne karte za atributivne karakteristike kvaliteta - Za karakteristike proizvoda, usluga ili procesa koje se ne mogu meriti već se samo opisno ocenjuju (dobro ili loše, ide ili ne ide) koriste se atributivne kontrolne karte. Ne rade se u paru i odnose se na broj ili procenat neusaglašenih proizvoda u uzorku i mogu biti:

- m karata predstavlja broj neusaglašenih primeraka uzor$\mathrm{ka}$;

- p karta koja predstavlja procenat neusaglašenih primeraka u uzorku $(\mathrm{p}=100 \mathrm{~m} / \mathrm{n})$;

- c karta ukupanog broj neusaglašenosti u uzorku;

- u karta koja predstavlja broj neusaglašenosti po jednom primerku u uzorku ( $\mathrm{u}=\mathrm{m} / \mathrm{n}),($ Kostić, 2004).

\section{KONCEPT ISTRAŽIVANJA}

Intervju. Ispitanici su odgovarali na usmeno postavljena pitanja iz upitnika. Prilikom intervjuisanja za osnovu upitnika uzeto je 12 kriterijuma iz MH modela izvrsnosti. Svaki kriterijum ima svoje podkriterijume koji su u ovom slučaju u funkciji pitanja/tvrdnje i ocenjuju se prema ček listi. Oblik i forma obrazaca su urađeni po uzoru na PROPR matricu koja se koristi u procesu samoocenjivanja, tako da je upitnik sadržao 960 pitanja. Na pocetku istrazivanja bilo je ukupno 12 kriterijuma, 112 podkriterijuma i 95 atributa, izloženih u osam reprezentativnih organizacija koje pokrivaju delatnost grafičke industrije Srbije. Uzorkovanjem je dobijeno 7.650 karakrestika koje su statistički obrađene metodom kontrolnih karata. Dobijeni odgovori predstavljaju podatke izražene procentualnim ocenjivanjem (1-100\%), koji će se pretvoriti u decimalne vrednosti u obraditi kontrolnim kartama.
Po završenom intervijuu dobili smo podatke koji će se dalje statistički obraditi metodom kontrolnih karata.

Primena statističke mere: Kontrolne karte. U ovom radu su korišćene kontrolne karte za praćenje numeričkih karakteristike kvaliteta i to: par. $\mathrm{x}$ : R kontrolnih karata koji se primenjuje na manjim uzorcima, $\mathrm{n} \leq 10$. Par karata se sastoji od kontrolne karte aritmetičke sredine (x) i kontrolne karte raspona (R). Sprovedeni intervju obuhvata 960 pitanja raspoređenuh u dvanaest grupa, što zbirno čini 7.650 podataka. Ocenjivanje je izraženo u procentima i zabeleženo u tabelama obrazaca za prikupljanje podataka. Nakon toga slede aktivnosti izrade kontrolne liste za kontrolne karte, pretvaranje vrednosti u decimalne brojeve, radi lakše manipulacije, i izrada samih kontrolnih karta za svaki od dvanaest kriterijuma. Ove statističke mere su urađene opštim načinom izrade kontrolne karte. Napomena: rađena je kontrolna karta za male uzorke $(n=5, n=10$ i $n=12)$ korišćenjem vrednosti tabele P2 kojom se izračunavaju vrednosti faktora kontrolnih granica (A2, D3, D4). Proračun je urađen korišćenjem alata Excel aplikacije. Za svaki od 12 kriterijuma urađene su najpre pomoćne karte za svaki pripadajući podkriterijum i na kraju zbirna kontrolna karta za glavni kriterijum. Rezultati kontrolnih karti su definisali procesne linije modela poslovne izvrsnosti. Najpre su urađena 922 proračuna i kontrolnih karti za aritmetičku sredinu i raspon što na kraju daje 1.844 proračuna i isto toliko kontrolnih karata.

U ovoj fazi je za dobijene rezultate primenjena statistička metoda kontrolne karte i pri tome je došlo do redukcije broja predloženih podkriterijuma i atributa koji su po normama statističke metode prelazili dozvoljene granice i vrednosti.

Rezime analize vrednosti dobijenih statističkom metodom kontrolne karte. Analiza dobijenih rezultata jasno razlikuje dve celine: rezultati kriterijuma koji pripadaju grupi mogućnosti organizacije (1-7 kriterijuma) odvajuju se od rezultata dobijenih od kritrijuma koji pripadaju grupi rezultati organizacije (8-12). To se jasno vidi na procesnim linijama.

Kod kriterijuma i podkriterijuma iz grupe mogućnosti organizacije, evidentna je veća dinamika kretanja tačaka i procesa oko proračunatih centralnih linija, pogotovo aritmetičkih sredina, i to u pripremnim sabiranjima samih uzoraka. Na tom nivou isključeni su pojedini podkriterijumi i atributi kako kasnije ne bi ometali tok procesa u odnosu na aritmetičku sredinu.

Karakteristika kriterijuma i podkriterijuma iz grupe rezultati organizacije, jeste mnogo ujednačenije prostiranje linija procesa oko srednje aritmetičke vrednosti, kao i povećan obim mogućih raspona na kontrolnoj karti raspona. U zbirnim operacijama nije zabeležena ni jedna ozbiljna tendencija, koja bi ukazala na isključivanje nekog podkriterijuma ili atributa. Razlog tome može biti i velika mogućnost raspona nastala usled prirode statističkih modela izračunavanja.

U oblasti zbira kriterijuma mogućnosti organizacije, koja sadrži sedam kriterijuma sa po deset podkriterijuma broj kriterijuma je ostao isti, dok se smanjio broj podkriterijuma za 16 (bilo ih je 70), a sada ih ima 54. U oblasti zbira kriterijuma rezultati organizacije na početku istraživanja bilo je 42 podkriterijuma smeštenih u 5 kriterijuma a sada ih ima 5 manje (37 podkriterijuma je ostalo nakon primene statističke metode). Ukupno od 112 podkriterijuma na početku istraživanja, zakonitostima statističke metode Kontrolne karte, otklonjen je 21 podkriterijum (19\%) i ostalo je 91 (81\%).

Pitanje atributa je imalo drugačiji pravac. Na početku istraživanja broj atributa je bio 10 u prvobitnoj oblasti zbira kriterijuma mogućnosti organizacije i 5 u oblasti zbira kriterijuma rezultati organizacije. Atributi su se ponavljali kroz pripadajuće kriterijume i podkriterijume u svakoj organizaciji, i to prvih deset zbirno 5.600 puta, a drugih pet 1.680. Došlo se do zaključka 
da je neophodno odstraniti (ili preformulisati) sledeće atribute: integrativno, inovativno i inovacije. Jasno je da se radi o smanjenju broja atributa za $20 \%$ što prikazuje sličnu vrednost u odnosu na procenat smanjenja podkriterijuma. Preporučuje se smanjenje 16 podkriterijuma i 5 atributa. Može se izneti preporuka, da je predložena prosečna vrednost za koju bi trebalo smanjiti broj podkriterijuma i atributa u novom modelu (prema prikazanooj statističkoj metodi kontrolne karte) prosečno za 19,5\% $\mathrm{u}$ odnosu na početne zahteve modela upitnika PROPR matrice $(19 \%+20 \% / 2)$.

Analizom slike 19. i 20. na kojima su predstavljene tendencije kretanja procesa na bazi MH modela izvrsnosti i PROPR matrice, $u$ početnom originalnom obliku (slika 18.) i nakon izvršenih korekcija (slika 20), stvorena je osnovna pretpostavka za razmišljanje o izradi modela poslovne izvrsnosti za grafičku industriju Srbije. Formiran je predlog modela poslovne izvrsnosti za grafičku industriju Srbije.

\section{JAZ GRAFIČKE INDUSTRIJE U SRBIJI I OKRUŽENJU}

Poslovno-tehnološki jaz. Tehnološki element je temelj oko koga bi trebalo graditi dalja nastojanja ka poslovnoj izvrsnosti. Dva su razloga za to: prvi je, da već postoji neka tehnološka infrastruktura na čijoj bazi se već posluje a i može se dalje nadgrađivati; drugi razlog je što tehnološke inovacije i razvoj već postoje (manje ili više zastupljene) i započele su promene u poslovanju voljno ili nevoljno u odnosu na grafičke kuće i grafičku privredu u celini. U grafičkoj industriji kao u retko kojoj grani privrede prisutan je trend novih tehnologija i to u svim sferama rada. Bez računara i softverskih pomagala, raznih IT elemenata danas nijedna grafička organizacije ne može i ne posluje, bez obzira šta proizvodi (od navedenih devet grupa grafičkog proizvoda) i u kom obimu izrađuje.

Kako je proizvodnja usko vezana za tehnologiju neminovno je očekivati da je najpre u području poslovno-tehnološkog jaza došlo do prelivanja potreba i dešavanja iz okruženja i na naše prostore. To je od posebnog značaja jer ovo područje nije bilo zapaženo kao proizvođač tehnologije (bar u sferi grafičke industrije), već kao korisnik proverenih dostignuća iz okruženja. U tom svetlu grafička industrija Srbije (i zemlja Srbija) pripada zemlji i organizacijama, definisanim kao "imitatori"u teoriji (teorija tehnološkog jaza i teorija životnog ciklusa proizvoda) i praksi. Grafička tehnologija (koja intezivno koristi IT u fazi pripreme proizvodnje) prilagođena je postojećoj infrastrukturi, tj. retko koja organizacija je imala mogućnost da nabavi standardazovanu novu tehnologiju. Nova (aktuelna) tehnologija koja se koristi u fazi pripreme grafičkog proizvoda uslovljena je primenom računara i adekvatnih uređaja, koji su ekonomski relativno dostupni i u velikoj su ponudi, te je iz tog razloga maksimalno podržana ova početna faza izrade grafičkog proizvoda. Kako su ostale faze (štampa i dorada) uslovljene mnogo skupljim i kompleksnijim mašinama/uređajima (samim tim i ekonomski teže dostupnim), pojavio se iznuđeni i privremeni način proizvodnje "polu-industrijski rad". Pod ovim izrazom podrazumeva se spektar aktivnosti i operacija koje se rade ručno, a u industrijskom su toku procesa. Angažovani su specijalisti i visko obučeni akteri za određene aktivnosti koji mogu uspešno da prate industrijski tok izrade u pravom trenutku i na adekvatan način. Ovo prelazno rešenje koristi se u serijskom načinu izrade grafičkih proizvoda i odraz je prilagođavanja ove industrijske grane posledicama tranzicionog nasleđa na ovim prostorima.

Organizacioni jaz. Predstavlja dobrovoljnu tržišnu barijeru, tako da sam čin prevazilaženja ove prepreke primorava organizaciju da primeni poslovanje kojim se obezbeđuje epitet "pouzdanosti u poslovanju”. Ovo je neophodna karakteristi- ka za pojavljivanje na međunarodnom tržištu. Prevazilaženje ovog nesklada između novog i starog načina poslovanja kao prvi uslov zahteva posedovanje aktuelne organizacione kulture. Kada su obezbeđeni navedeni uslovi pristupa se integtaciji i usklađivanju neophodnih standarda, njihovih pripadajućih MS sa menadžmentom organizacije. Navedeni put implementacija standarda sistema, ide najpre prihvatanjem standarda sistema kvaliteta ISO 9001 i QMS zato što on “priprema teren” tj. organizaciju za dalje prevazilaženje ovog jaza.

On menja osnovni pristup poslovanja jer inicira:

- procesni pristup u sagledavajnja aktivnosti organizacije;

- pretvara kontrolni u preventivni pristup stvaranja kvaliteta.

Prateći vrednosti uzorkovanih organizacija (vodećim u grafičkoj industriji Srbije) primećeno je da je većina organizacija $(87,5 \%)$ uvela u svoje poslovanje ISO 9001. Ostali standardi su zastupljeni u manjem obimu (ISO 14001, OHSAS 18001, HACCP, ISO 2200, itd.). U grafičkoj industriji Srbije nije zabeležena nijedna organizacija koja je implementirala IMS i standard ISO 9004:2009.

Uzrok ovakvom stanju nije samo ekonomsko ograničenje, već i neodgovarajuća organizaciona kultura i nedostatak lidera/ rukovodilaca koji će shvatiti značaj standarda i uložiti energiju za njihovo implementiranje. Ponekad uvođenje standarda predstavlja obavezu koja će omogućiti poslovanje na međudržavnom tržištu. Uspeh u primeni standarda zavisi od stava lidera/rukovodstva. Najčešći oblik učenja lidera vezuje se za neke tehnologije ili načine poslovanja, sa kojim se susreću pri nabavci repromaterijala ili mašina u inostranim zemljama, koje pokušavaju da sprovedu u svojim organizacijama.

Iz navedenih razloga, najbolje rezultate daju takozvane "firme ćerke”, koje su delovi već razvijenih sistema. One prihvataju i sprovode organizacionu kulturu svojih centrala i time utiču na svoje poslovno okruženje. Primenjuju "obavezne standarde" i načine poslovanja u čemu im finansijski i edukacijom pomaže "baza". Takvim načinom poslovanja one prenose svoje zahteve na partnere i saradnike u okruženju i postaju model poslovanja koji evidentno donosi materijalnu i duhovnu dobit.

Za dalji razvoj poslovanja, formiranje modernog društva i postavljanje zdravih osnova, možda je idealna upravo krizna situacija u kojoj se nalazi naše poslovno i društveno okruženje. Kako su ove aktivnosti povezane sa preobražajem čitavog društva neophodan je širi pristup i edukovanje, gde bi država trebalo da obezbedi uslove, nauka da podeli saznanja, a privreda da zahteva i prihvata neophodna znanja i veštine za svoje obitavanje.

Organiazacioni element je pre par decenija utemeljio svoje prisustvo na ovim prostorima i odvija se u granicama svojih maksimalnih mogućnosti, koje su uslovljene ekonomskim okolnostima. Ponekad se iznosi netačna tvrdnja kako "organizacije neće” da primene određene standarde, MS i procedure. Dozvoljava se mišljenje da je ova tvrdnja bila izražena na početku uvođenja zahteva za standardima na ovim prostorima (1990-2001). Podsećamo da je grafička industrija Srbije preživela jednovremeni proces vlasničke, tržišne i tehnološke transformacije u drugi politički sistem. U početnom periodu ovih procesa nestale su mnoge "državne i društvene grafičke organizacije", a iznikao je veliki broj mikro organizacija koje su pokušale da nastave poslove ugašenih grafičkih organizacija. Grafičke organizacije koje su nastavile kontinuitet u radu prošle su (i prolaze) kroz vlasničke i organizacione promene poslovnih sistema. Nove grafičke organizacije su se susrele sa velikom nedoumicom u poslovanju kada su shvatile da je smanjenje kapaciteta teritorije proporcionalno smanjilo i veličinu domaćeg tržišta. Većina njih nije bila spremna ili nije bila u ekonomskoj, menadžerskoj i poslovnoj mogućnosti da pokrene poslovanje na inostranom tržištu. Razlog 
je jasan - na čelu novonastalih grafičkih organizacija uglavnom su se nalazili niži rukovodioci koji su poznavali samo način poslovanja koji je bio primenjen u nekadašnjim velikim grafičkim kućama. Princip dogovorne ekonomije (i korupcije) primenjivan je na ovim prostorima u velikom obimu. Pojava standarda je tada tumačena kao nametanje nepotrebnih troškova, promenu načina poslovanja i izbegavana je uz obrazloženje "kako se neće raditi za inostrano tržište" i da su standardi neophodni samo “tamo". Ključan razlog odbijanja implementacije standarada bio je nedostatak edukacije, menadžera i Lidera u tom vrmenskom trenutku. Vremenom, prateći zahteve i promene u okruženju veće grafičke organizacije postaju ili vlasništvo inostranih istorodnih kompanija ili se opredeljuju za upliv u regionalno/globalno tržište. Obrazuju se i kadrovi koji prepoznaju principe, oblike i zahteve novog tržišta i implementiraju svoje znanje i umeće u grafičke organizacije. Novi menadžeri, inženjeri, lideri suočeni sa tržišnim barijerama, zalažu se i implementiraju neophodne standarde i MS u strukture poslovanja grafičkih organizacija. Oni uspešno kombinuju zatečenu infrastrukturu i "polu industrijski način” (prelazni element) izrade grafičkih proizvoda sa novom tehnologijom i grade potpuno nove kulture poslovanja.

Veoma važan faktor u promeni svesti i razmišljanju zaposlenih sa ovih prostora jeste upliv stranog kapitala i kompanija na ove prostore. Strane kompaine su sa sobom donele i drugačiji, aktuelni način poslovanja, poslovnih običaja i navika koje je domaća privreda morala da prihvati: od radnog vremena, kodeksa ponašanja, poštovanja ljudskih prava, itd. Svojim radom u inistranim organizacijama zaposleni prihvataju i nova mišljenja, shvatanje novog drugačijeg poslovanja i time povećavaju nivo društvene odgovornosti. Permanentni kursevi i drugi različiti oblici edukacije i postoje da bi zaposleni lakše prihvatili organizacionu kulturu i shvatili procese i načine rada organizacija. Dolazi do promene razmišljanja zaposlenih, menjaju se njihovi prioriteti (i kada su u ulozi potrošača), zahtevi, formira se novi društveni ambijent (Čudanov, 2012).

\section{KULTUROLOŠKI JAZ}

Sledeći korak u aktivnosti smanjenja jaza jeste pitanje organizacione kulture. Oko postojećeg tehnološkog jezgra trebalo bi graditi novu kulturu organizacije. Lider/rukovodstvo su ključni elementi za racionalni nastavak menjanja stare i građenja nove kulture organizacije. U savremenim organizacijama pojmovi Lider/rukovodstvo se vezuju za promene. Oni su ti koji prilagođavaju organizacije promenama u okruženju a i sami kreiraju promene. Od njih se i u slučaju poslovanja grafičke organizacije očekuje da vode proces promena za korak ispred drugih. Njihova edukacija i sposobnost obezbeđuju im dugoročno planiranje i razmišljanje. S obzirom da prepoznaju "da je zalaganje za očuvanje status quo stanja pogubno u uslovima turbulentnih promena u okruženju" moraju ovo shvatanje da podele sa svim zaposlenima. Neophodno je da lider grafičke organizacije, sa jedne strane bude edukovan iz oblasti čime se ta organitzacija bavi, a sa druge strane da dobro poznaje privredne aktivnosti u privrednoj grani i celokupnom društvu i da oko sebe okupi tim sastavljen pretežno od tkzv. T-inženjera. Pojava problema pokretanja značajnih organizacionih promena leži generalno (i u grafičkim organizacijama) u činjenici da u našim organizacijama postoji veliki broj rukovodilaca (menadžera), a mali broj lidera. Ove promene se teže sprovode u većim nego u manjim poslovnim sistemima, jer njihova struktura zaposlenih sadrži veliki broj rukovodilaca/šefova sa uskogrudim načinom razmišljanja, okrenutih internim problemima i birokratiji. Po pravilu ove organizacije imaju malo ili nedovoljno Lidera, pokretača neophodnih promena.
Kultuloroški jaz je nivo prepreka koje se mogu pevazići jedino ako je društvo razvijeno do te mere da je organizaciona kultura na zavidnom nivou, da je organizacija "ona koja uči", da su u poslovanju prisutne permanentne i sistemske inovacije i poboljšanja. U takvim uslovima može se realno primeniti TQM koncept koji će dovesti do tranzicije menadžmenta kvaliteta u kvalitet menadžmenta korišćenjem kriterijuma modela poslovne izvrsnosti.

Navedeni zahtevi ne smeju obeshrabriti napore u dobrom poslovanju organizacija koje su krenule putem izvrsnosti i u nepripremljenom okruženju (kao što su ovi prostori). Naprotiv, napori ka poslovnoj izvrsnosti moraju unaprediti i tretirati kao uzor i primer težnji ka dobrom poslovanju. U tom pravcu se realizuje izrada poslovnog modela izvrsnosti grafičke industrije Srbije, kako bi ona definisala svoje "najbolje" organizacije, okupila ih u neku društvenu organizaciju (npr. nacionalni grafički klaster), kako bi organizacije lakše ostvarile bolje načine poslovanja.

Organizaciona kultura predstavlja temelj stvaranja imidža i identiteta svake organizacije. Izgradnjom organizacione kulture definišemo pozitivni identitet organizacije, način poslovanja i celokupni poslovni ambijent koji se reflektuje na širu društvenu zajednicu. Iz interne kulture organizacije proističe njena prepoznatljivost na tržištu što je jedna od važnih karakteristika svake organizacije (npr. Politika, Novosti). Ona predstavlja zajedničko viđenje članova jedne poslovne organizacije, utiče na način ponašanja zaposlenih, skup vrednosti, simbola, rituala, mitova i prakse. Promoteri izgradnje organizacione kulture moraju biti lider i rukovodstvo organizacije. Ne postoji "idealna organizaciona kultura”, već odgovarajuća organizaciona kultura. Lider i rukovodstvo moraju dati primer i model organizacione culture, širenjem etičkog ponašanja među zaposlenima kroz obuku, javne nagrade i kažnjavanje neetičkog ponašanja.

Ukoliko vremenom ne evoluira, organizaciona kultura može postati barijera internim promenama.

\section{PROMENA ORGANIZACIONE KULTURE}

Faza odmrzavanja. U početnoj fazi procesa promene organizacione kulture, rukovodstvo mora da pospeši razumevanje i analizu postojeće kulture kod zaposlenih. Prikazivanjem internih karakteristika organizacije dolazi se do spoznaje ograničenosti poslovne i proizvodne sposobnosti organizacija. Prisutan je nedostatak procesnog doživljavanja organizacije. Poznate su činjenice koje otežavaju početni korak: nasleđena infrastruktura, znanje u skladu sa starom tehnologijom rada, pridruživanje starih normi, prevaziđen asortiman proizvoda, nepoverenje prema novom, nedostatak novih tehnologija, nedostatak obrazovanog osoblja "sa širinom", mnogo specijalista koji se koriste u poluindustrijskom radu, itd. Neophodno je da zaposleni prihvate prevaziđenost i zastarelost postojeće kulture organizacije, koje često nisu svesni, već je doživljavaju kao svoj drugi dom (prilagođavajući radnu okolinu komoditetima iz privatnog života).

Nastupajuća promena se uglavnom doživljava kao negiranje prošlosti i lični gubitak. U ovoj fazi lideri/rukovodioci moraju posebno ispoljiti energičnost i upornost ukazujući ličnim primerom na ispravnost promena. Na kraju, zaposlene treba sistematski i primerom upoznati sa prednostima nameravane promene uz prezentovanje već (sličnih) postignutih rezultata. Time se obezbeđuje podrška zaposlenima i timovima koji imaju viziju o neophodnosti bolje organizacione kulture.

Prihvatanjem ograničenja i karakteristika zastarele kulture i definisanjem željene kulture, organizacija identifikuje ,jaz kulture” koji je neophodno prevazići (Čudanov, 2012; Stanojković, 2014). 
Faza promena i sprovođenja. Neophodno je da u ovoj fazi Lider/rukovodstvo pokažu energičnost i nepokolebljivost uz veliku dozu kompetentnosti.Poželjno je da se preduzimaju aktivnosti i potezi sa brzo vidljivim rezultatima kao što je npr. racionalizacija administracije na funkcionalni nivo reinženjeringom celokupne organizacione strukture. Lider mora razvijati odgovornost zaposlenih uz njihovo uvažavanje i uključivanje u donošenje odluka, biranjem najboljih pojedinaca za vođe timova. Na taj način se diferencira "kritična masa pojedinaca" koji su najbolje shvatili i prihvatili predstojeću promenu organizacione kulture i koji će izneti najveći teret njenog novog uspostavljanja. Ovi zaposleni čine zdravu osnovu za dalji razvoj interne kulture organizacije deljenjem znanja u novonastaloj organizacionoj kulturi. Neophodna je izgradnja raznih modela za iznošenje raznovrsnosti i stimulacije u poslovanju, kooperacija zaposlenih, umesto konkurencije.

Faza zamrzavanja. U ovoj fazi neophodno je da zaposleni prihvate novi kulturni obrazac kao deo svakodnevnice. Zamenom tradicionalnog načina funkcionalnog organizovanja poslovnog sistema (u većini slučajeva) i primenom procesnog pristupa poslovanju organizacija je kročila u novu kulturu poslovanja. Ukidaju se oštre granice između organizacionih celina, poništavaju se zastarele mentalne strukture rada „mi protiv njih" i pojava konkurencije među organizacionim celinama. $\mathrm{Na}$ kraju se menjaju tradicionalne vrednosti, verovanja, i dotadašnji načini obavljanja poslova, što je suština prilagođavanja organizacije promenama u okruženja. Kultura usmerava organizaciju i postaje njen operativni sistem. Sledi kreiranje novih kodeksa i normi ponašanja, simbola ili prioriteta, čime se demonstrira raskidanje veza sa starim načinom poslovanja i učvršćuje se nova organizaciona kultura. Da bi demonstrirali posvećenost promeni kulture neophodno je pokazati odlučnost u promenama. Primer: fizičke-vidljive promene u organizaciji kao što su zamena starih mašina novom tehnologijom ili promena ključnih osoba (operatera, menadžera) čime pokazujemo odlučnost u akciji prema zaposlenima. U grafičkoj industriji Srbije prisutna je velika raznolikost u strukturi poslovanja. Proizvodi grafičke industrije su zastupljeni u svim domenima poslovanja, što čini specifično održavanje poslovno-tehnološkog nivoa organizacija, koje se bave izradom grafičkih proizvoda. Svaka organizacija je različita i ima svoje specifičnosti koje proizilaze iz kulturnog obrasca same organizacije. Postoji više modela organizacione kulture koji se primenjuju u upravljanju grafičkim organizacijama u zavisnosti "šta" i "kako" organizacija proizvodi: knjige, časopise, kutije, PVC kese, vreće, omote, brošure, salvete, registratore, fascikle, blokove, obrasce, itd. (Čudanov, 2012).

Jaz raznolikosti i društvene odgovornosti. Globalizacija dovodi do promena u svim sferama života ljudi, svet se razvija u pravcu većeg međusobnog uticaja, a vreme i prostor gube na značaju. Razvoj komunikacione tehnologije doprinosi zbližavanju, uvećanju znanja, nudi načine i modele za razvoj ljudskih sposobnosti. U takvim okolnostima postavlja se pitanje, može li se raznolikost odupreti globalizaciji? Različiti načini na koje pristupamo ovoj kompleksnoj realnosti dovode do različitih ishoda. $\mathrm{Na}$ ovim prostorima (južnog Balkana) odavno žive i rade ljudi različitog kulturnog porekla. Migracija stanovništva iz jedne zemlje u drugu i dalje je aktuelna zbog skorašnjih dešavanja na ovom prostorima. Tradicionalni oblici pripadnosti se ruše ili uklapaju u neki novi kulturalni oblik, gde pojedinac donosi odluku o mestu na kome će živeti. Pojedinac kao deo društva postaje odgovoran za društvo u kome živi s obzirom na međuzavisnost današnjeg sveta i neophodnost dubokog poštovanja različitosti.

Oslonac ovakvog bitisanja potrebno je prepoznati u Konvenciji o zaštiti i promovisanju raznolikosti kulturnih izraza i aktuelnih propisa (UNESCO, 2005).
Neophodno je napraviti razliku između pojma raznolikost i različitost. Pojam raznolikosti je misao o raznom (spektar nečega) i predstavlja kulturološko bogatstvo, a ne suprostavljen entitet (vrlo čest stereotip). Manipulacija raznolikošću dovodi kulturno nasleđe $\mathrm{u}$ središte kulturnih podela i ima negativan uticaj na psihologiju ljudi i stvaranje nepotrebnih stereotipa društva. U prevazilaženju ovog jaza neophodna je primena nove strategije totalnog kvaliteta (TQS) koja se zasniva na porastu društvene svesti zajednice u okviru koje organizacija obitava.

Društvena svest mora da sažme dve sfere življenja:

- podsticanje tradicionalnih razlika između ljudi različitih zajednica (prilaz odozdo);

- rast društvene odgovornosti i unapređenje performansi životne sredine (prilaz odozgo). Kako je organizacija deo društvene zajednice ona mora (prilikom savladavanja jaza raznolikost i društvene odgovornosti) težiti obezbeđivanju optimalnog i inspirativnog radnog okruženja svim zaposlenima. Svoje namere organizacija objavljuje i prikazuje u obliku raznih kodeksa rada i ponašanja široj društvenoj javnosti raznolikim medijumima. Primer: Generali Grupa Kodeks ponašanja (Čudanov, 2012; Stanojković, 2014).

Zadovoljenje uslova raznolikosti i društvene odgovornosti. Prema popisu iz 2011. godine (Bez Kosova i Metohije), na ovim prostorima obitavaju: Srbi (6,0 miliona, 83,3\%) ), Mađari (253,9 hiljada ili 3,5\%), Romi (147,6 hiljada ili 2,1\%) i Bošnjaci (145,3 hiljada ili 2,0\% ), dok ostale nacionalnosti participiraju sa ispod $1 \%$ zastupljenosti, Hrvati (57,9 hiljada ili $0,8 \%)$, Slovaci $(52,8$ hiljada ili 0,7\%), Crnogorci (38,5 hiljada ili 0,5\%, Vlasi (35,3 hiljada ili 0,5\%) (Knjiga 4, RSZ). Poštovanje kulturoloških razlika, poštovanja ljudskih prava i prava manjinskih grupa, solidarnosti, načela jednakih prava za sve, aktivnog učešća i demokratije su aktivnosti za koje je neophodno učešće celokupnog društva i institucija države.

Fomiranje klastera i inkubatora grafičke industrije neophodni je korak ka boljoj organizaciji grafičkih organizacija čime bi one aktivnije upravljale svojim interesima u odnosu na dobavljače, konkurenciju i ostala tržišna ograničenja. Treba napomenuti da je angažovanje države prirodno i neophodno u obezbeđivanju uslova za poslovanje celokupne privrede.

Država bi trebalo da stvori ambijent, rukovodi i pospešuje aktivnosti za uvođenje i upravljanje dostignutim nivoom kvaliteta (implementacijom standarda/sistema). Preporuka je da se na nivou države oformi telo za upravljanje sistemom kvaliteta grafičkih organizacija (u Ministarstvu industrije i/ili Priprivrednoj komori). Na ovaj način, telo bi se bavilo popularizacijom, motivacijom, problemima sprovođenja, obukom i savetovanjem. Njega bi činili multidisciplinarni timovi stručnjaka, sposobni da svakoj grafičkoj organizaciji pomognu u rešavanju tekućih i dugoročnih problema.

\section{REZULTATI I DISKUSIJA}

Rezime istraživanja: Sagledavši prikazane oblike jaza između aktuelnih svetskih zbivanja i grafičke industrije Srbije, uočava se da je stepen primene aktivnosti sledeći: najviše je urađeno u savladavanju poslovno-tehnološkog jaza, zatim nešto manje kod anuliranja orgnizacionog jaza, još manje na nivou kulturoloških zbivanja i možda najmanje u savladavanju razmaka između krajnjih tačaka (raznolikosti i društvene odgovornosti).

Ovako zatečeno stanje može se objasniti sledećim zapažanjima.

Opšti izgled tabele: Kontrolna lista oscene MH kriterijuma, kontrolne karte i uporedni prikaz kriterijuma MH modela i kriterijuma paradigme modela izvrsnosti. 


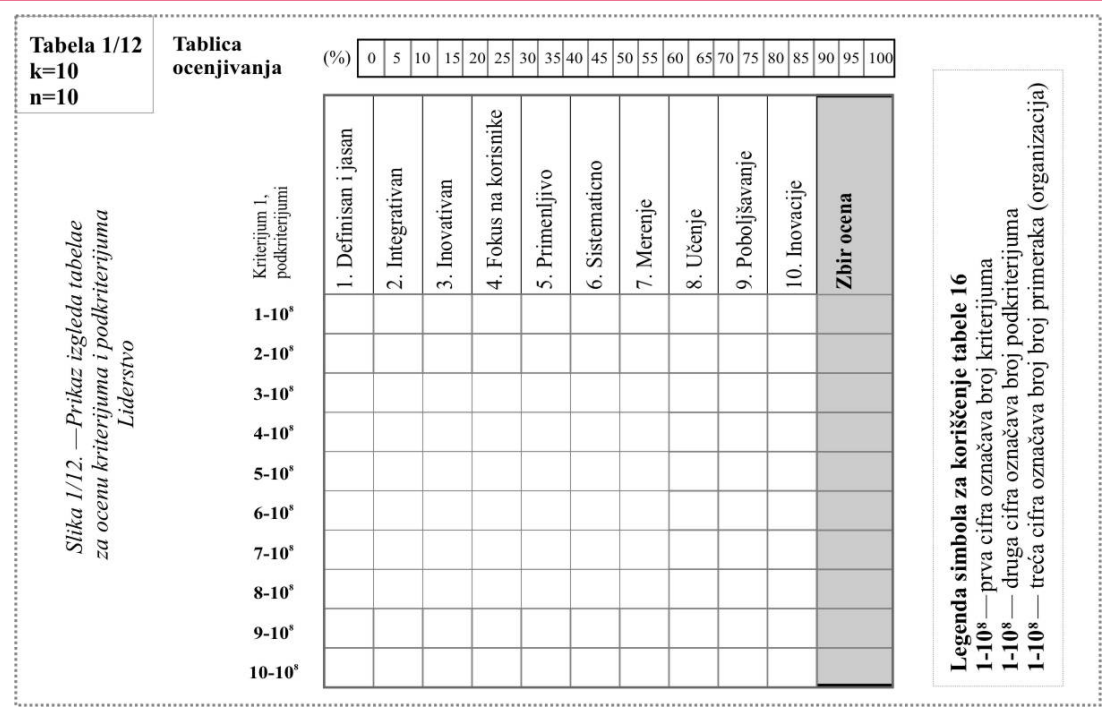

Tabela1. Kontrolna lista ocene MH kriterijuma

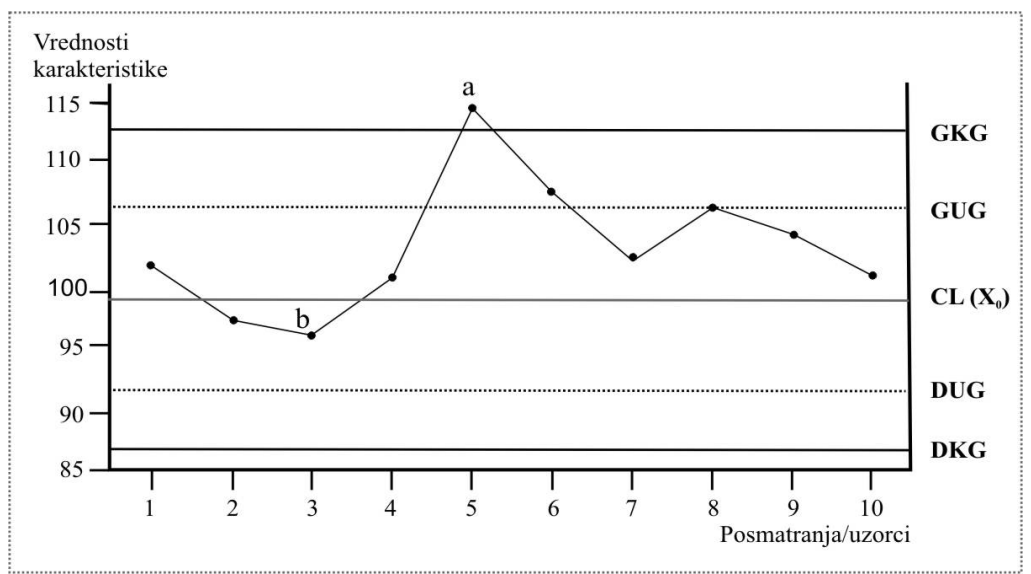

Tabela 2. Opšti izgled kontrolne karte

\begin{tabular}{|c|c|c|}
\hline $\begin{array}{c}\text { Model } \\
\text { izvrsnosti }\end{array}$ & Struktura modela izvrsnosti & $\begin{array}{c}\text { Broj } \\
\text { poena/procenata }\end{array}$ \\
\hline & $\begin{array}{l}\text { 1. Liderstvo, } \\
\text { 2. Orijentacija na kupca i partnerstvo, } \\
\text { 3. Vizija i strategija, } \\
\text { 4. Ljudi, } \\
\text { 5. Resursi, } \\
\text { 6. Procesi, } \\
\text { 7. Kontinualna poboljšanja i inovacije, } \\
\text { 8. Proizvodi, } \\
\text { 9. Rezultati prema kupcima, } \\
\text { 10. Rezultati u odnosu na ljude } \\
\text { 11. Reziltati u odnosu na društvo } \\
\text { 12. Performanse ključnih rezultata }\end{array}$ & $\begin{array}{c}100 /(10 \%) \\
70 /(7 \%) \\
70 /(7 \%) \\
70 /(7 \%) \\
60 /(6 \%) \\
100 /(10 \%) \\
80 /(8 \%) \\
100 /(10 \%) \\
120 /(12 \%) \\
60 /(6 \%) \\
50 /(5 \%) \\
120 /(12 \%)\end{array}$ \\
\hline & ZBIR: & $1000(100 \%$ \\
\hline \multirow{3}{*}{ 唡 } & $\begin{array}{l}\text { 1. Plašt mogućnosti organizacije: } \\
\text { 1.1. Liderstvo, } \\
\text { 1.2. Strategija i orijentacija na kupca, } \\
\text { 1.3. Ljudi, } \\
\text { 1.4. Partnerstvo i resursi, } \\
\text { 1.5. Proces, } \\
\text { 1.6. Kontinualna poboljšanja i inovacije. }\end{array}$ & $\begin{array}{c}\frac{1-\mathbf{6 0 0}(\mathbf{6 0} \%)}{90(9 \%)} \\
90(9 \%) \\
90(9 \%) \\
100(10 \%) \\
140(14 \%) \\
90(9 \%)\end{array}$ \\
\hline & $\begin{array}{l}\text { 2. Plašt ostvarenih rezultata organizacije: } \\
\text { 2.1. Rezultati u odnosu na proizvod, } \\
\text { 2.2. Rezultati prema kupcima, } \\
\text { 2.3. Rezultati u odnosu na ljude, } \\
\text { 2.4. Reziltati u odnosu na društvo, } \\
\text { 2.5. Vrednost ključnih rezultata. }\end{array}$ & $\begin{array}{c}\frac{2-\mathbf{4 0 0}(\mathbf{4 0} \%)}{100(10 \%)} \\
100(10 \%) \\
50(5 \%) \\
50(5 \%) \\
100(10 \%)\end{array}$ \\
\hline & ZBIR: & $\begin{array}{c}(1+2) \\
1000 /(100 \%)\end{array}$ \\
\hline
\end{tabular}

Tabela 3. Uporedni prikaz kriterijuma MH modela i kriterijuma paradigme modela izvrsnosti 


\section{ZAKLJUČAK}

$\mathrm{Na}$ osnovu primenjene statističke metode (kontrolne karte) $\mathrm{i}$ analizom postojećeg razmatranja jaza organizacija grafičke industrije i okruženja možemo dati odgovor na hipotezu: da li je moguća primena modela poslovne izvrsnosti na grafičke organizacije u Srbiji?

$\mathrm{Da}$, postoje realni uslovi za primenu modela poslovne izvrsnosti na grafička organizacija Srbije.

U tu svrhu je izrađena i paradigma modela poslovne izvrsnosti karakteristične za grafičku industriju.

Angažovanje državnih institucija obezbeđivanjem uslova za bolje poslovanje umnogome bi pomoglo privrednim aktivnostima svih organizacija na ovim prostorima.

\section{LITERATURA}

Čudanov, M. (2012). Organizaciona kultura i etika. Master rad, Fakultet organizacionih nauka. Beograd.

Heleta, M. (2008). Menadžment kvaliteta. Beograd: Univerzitet Singidunum.

Heleta, M. (2010). TQM Modeli izvrsnosti i integrisani menadžment sistemi. Beograd: Zavod za udžbenike.

Kostić, M. (2004). Metode i tehnike za poboljšanje kvaliteta. Beograd: Viša politehnička škola.

Stanojković, S. (2014). Modeli izvrsnosti i samoocenjivanje u grafičkoj industriji Srbije. Pristupni rad, Univerzitet Singidunum, Beograd. 